\title{
The Optimal Type and Management of Biliary Drainage in Patients With Obstructive Jaundice Who Undergo Pancreaticoduodenectomy
}

\author{
DAISUKE SATOH, HIROYOSHI MATSUKAWA and SHIGEHIRO SHIOZAKI
}

\author{
Department of Gastroenterological Surgery, Hiroshima City Hiroshima Citizens Hospital, Hiroshima, Japan
}

\begin{abstract}
Background/Aim: The aims of this study were to clarify optimal type and management of preoperative biliary drainage $(P B D)$ in patients with obstructive jaundice who underwent pancreatoduodenectomy $(P D)$. Patients and Methods: A total of 156 patients with obstructive jaundice who underwent PD were enrolled. We compared clinical variables and postoperative complications between patients who underwent endoscopic retrograde biliary drainage (ERBD) and those who underwent endoscopic nasobiliary drainage (ENBD). Results: All patients underwent PBD, with $E R B D$ in 117 and ENBD in 39. The incidence of infectious complications and clinically relevant pancreatic fistula $(C R-$ $P F)$ were significantly higher in the ERBD group (39\% vs. $13 \%, p=0.012$ and $39 \%$ vs. $10 \%, p<0.00001$, respectively). However, there was no significant difference in the postoperative complications between two groups when the duration of drainage exceeded 30 days. Conclusion: ERBD should not be performed in patients with obstructive jaundice prior to PD because of the increased rates of infectious complications and CR-PF following PD, and ENBD should be chosen instead. Furthermore, PD should be performed within 30 days of drainage period in patients with ENBD.
\end{abstract}

Biliary tract obstruction, which can cause substantial mortality and morbidity (1-3), is frequently encountered in patients with periampullary cancer. It has been reported that up to $70 \%$ of patients have some degree of biliary obstruction at the time of their initial diagnosis of pancreatic

This article is freely accessible online.

Correspondence to: Daisuke Satoh, MD, Department of Gastroenterological Surgery, Hiroshima City Hiroshima Citizens Hospital, 7-33 Motomachi, Naka-ku, Hiroshima, Japan. Tel: +81 822212291, Fax: +81 822235514, e-mail: ddds4863@gmail.com

Key Words: Pancreaticoduodenectomy, preoperative biliary drainage, type of biliary drainage. cancer (4). Therefore, biliary stents are often placed in patients with obstructive jaundice preoperatively to relieve their symptoms such as pruritus and jaundice, which would improve surgical outcomes by overcoming the impaired immune response and coagulopathy associated with cholestasis (5).

However, biliary stents have been found to be a significant risk factor for bacterobilia, which can result in postoperative infectious complications after pancreaticoduodenectomy (PD) (6-10). It has also been reported that biliary infection, which might be evoked by preoperative biliary drainage (PBD), was significantly associated with clinically relevant pancreatic fistula (CR-PF) after PD (11-15). Van der Gaag performed a trial that randomized 94 patients to either early surgery without PBD or to PBD with delayed surgery. The rate of cumulative serious complications at 120 days was significantly higher in the PBD group than in the early surgery group. However, the difference was attributed to a very high complication rate associated with $\mathrm{PBD}$ procedures before surgery, rather than differences in the rate of postoperative complications (16). Moreover, some authors have claimed that PBD itself was not related to increased morbidity and mortality rates after PD, though positive bile cultures were associated with infectious morbidity, overall morbidity, and mortality (17).

Although its effect is still controversial, PBD is often inevitable in clinical practice because of the ongoing cholangitis, neoadjuvant therapy, etc. Recently, endoscopic drainage is selected first. Percutaneous transhepatic drainage is adopted only when endoscopic drainage in not possible. There are two different ways of endoscopic drainage: endoscopic retrograde biliary drainage (ERBD) and endoscopic nasobiliary drainage (ENBD). However, there is no consensus about which of the two drainage methods should be performed when PBD is inevitable. It is necessary to inform clinicians about the optimal type of biliary drainage in regard to postoperative complications and the useful management of PBD in patients with obstructive jaundice who undergo PD. 
Table I. Patient characteristics.

\begin{tabular}{lccc}
\hline & $\begin{array}{c}\text { ERBD } \\
(\mathrm{n}=117)\end{array}$ & $\begin{array}{c}\text { ENBD } \\
(\mathrm{n}=39)\end{array}$ & $p$-Value \\
\hline Age, median (range), years & $70(32-87)$ & $71(52-87)$ & $17 / 22$ \\
Gender (male/female), $\mathrm{n}$ & $75 / 42$ & $22(17-28)$ & 0.217 \\
Body mass index (range), kg/m ${ }^{2}$ & $22(15-33)$ & $15(38 \%)$ & 0.025 \\
Pancreatic cancer, $\mathrm{n}(\%)$ & $63(54 \%)$ & $19(49 \%)$ & 0.136 \\
Preoperative cholangitis, $\mathrm{n}(\%)$ & $53(45 \%)$ & $4(1.7-10)$ & 0.711 \\
Diameter of MPD, median (range), mm & $3(1.5-10)$ & $26(67 \%)$ & 0.327 \\
Soft pancreatic parenchyma, $\mathrm{n}(\%)$ & $73(62 \%)$ & $7.0(4.7-27.1)$ & 0.630 \\
Total bilirubin before drainage, median (range), mg/dl & $6.4(2.9-30.5)$ & $1.6(0.3-8.0)$ & 0.221 \\
Total bilirubin at the time of surgery, median (range), mg/dl & $0.9(0.2-8.1)$ & $17(44 \%)$ & 0.0002 \\
EST, $\mathrm{n}(\%)$ & $108(92 \%)$ & $21(54 \%)$ & 0.405 \\
Stent exchange, yes, $\mathrm{n}(\%)$ & $54(46 \%)$ & $26(8-184)$ & 0.091 \\
Duration of drainage, median (range), days & $33(8-438)$ & \\
\hline
\end{tabular}

MPD: Main pancreatic duct; EST: endoscopic sphincterotomy; ERBD: endoscopic retrograde biliary drainage; ENBD: endoscopic nasobiliary drainage.

The aims of this study were to clarify optimal type and management of PBD in patients with obstructive jaundice who underwent PD.

\section{Patients and Methods}

A total of 156 patients with obstructive jaundice who underwent PD for either benign pancreatic disease or malignant periampullary and pancreatic neoplasms in our institution from January 2005 to December 2019 were retrospectively analyzed. The study protocol was approved by the Clinical Research Ethics Committee of our hospital (approval number: 2019-147).

The method of endoscopic biliary drainage was decided by the endoscopists. The patients who underwent PBD were discharged and waited at home until their operation was possible.

Clinical variables including patients' characteristics, intraoperative biliary culture, postoperative morbidity and infectious complications, and the incidence of CR-PF were evaluated. Bile was sampled when the bile duct was divided during surgery and sent for Gram staining and culture.

Prophylactic antibiotics were administered to all patients and selected according to the susceptibility of the bacteria in preoperative bile cultures. In patients with negative preoperative bile cultures, a first-generation cephalosporin (cefazolin sodium hydrate) was administered.

Postoperative morbidity and mortality were defined as complications or deaths occurring within 30 days after operation or during the hospital stay. Infectious complications included postoperative pneumonia, urinary tract infection, and wound infection, bacteremia, intraabdominal abscess. All complications were defined according to the criteria proposed by Clavien and Dindo (18). Pancreatic fistula and delayed gastric emptying were defined according to the definitions of the International Study Group on Pancreatic Fistula.

Continuous data are expressed as means \pm standard deviation (SD) and were compared using the Mann-Whitney $U$-test. Categorical data were assessed using the chi-squared test. Statistical analysis was carried out using JMP software (version 9.0; SAS Institute, Inc., Cary, NC, USA).

\section{Results}

A total of 156 patients (male, $n=92$; female, $n=64$ ) were enrolled in this study. All patients underwent PBD, with endoscopic retrograde biliary drainage (ERBD) in 117 and endoscopic nasobiliary drainage (ENBD) in 39.

There were no significant differences in age, body mass index, diameter of the main pancreatic duct, serum total bilirubin level before drainage, or the ratio of patients with pancreatic cancer, preoperative cholangitis, soft pancreatic parenchyma, and stent exchange between the ERBD group and the ENBD group. However, the ERBD group had a male predominance $(p=0.025)$, low total bilirubin at the time of surgery $(0.9 \mathrm{mg} / \mathrm{dl})(p=0.0002)$, a high rate of performing endoscopic sphincterotomy (EST) (92\%) $(p<0.0001)$. Duration of drainage was relatively longer in the ERBD group than in the ENBD group though the difference was not significant (Table I).

In the ERBD group, operative time was slightly longer, and the amount of blood loss seemed to be greater, moreover, the serum levels of C-reactive protein on postoperative day 1, 3 and 5 were significantly higher than those in the ENBD group. Though there was no significant difference in amylase levels in the drainage on postoperative days 1 and 3. The incidence of CR-PF after PD was significantly greater in the ERBD group than in the ENBD group ( $39 \%$ vs. $10 \%, p<0.0001)$. Furthermore, the incidence of infectious complications was significantly greater in the ERBD group than in the ENBD group (39\% vs. $13 \%$, $p=0.012$ ). In particular, there were significantly more patients with wound infection and intra-abdominal abscesses in the ERBD group than in the ENBD group. Total hospital stay was not significantly different between the two groups (Table II). 
Table II. Operative details and postoperative morbidity.

\begin{tabular}{|c|c|c|c|}
\hline & $\begin{array}{c}\text { ERBD } \\
(\mathrm{n}=117)\end{array}$ & $\begin{array}{l}\text { ENBD } \\
(\mathrm{n}=39)\end{array}$ & $p$-Value \\
\hline \multicolumn{4}{|l|}{ Operative details } \\
\hline Operative time, median (range), min & $505(319-797)$ & $477(275-824)$ & 0.102 \\
\hline Blood loss, median (range), ml & $790(80-6,005)$ & $610(170-3,140)$ & 0.146 \\
\hline \multicolumn{4}{|l|}{ C-reactive protein, median (range), $\mathrm{mg} / \mathrm{dl}$} \\
\hline POD 1 & $7.4(3.1-29)$ & $6.7(1.0-17.1)$ & 0.032 \\
\hline POD 3 & $17.0(2.2-33.8)$ & $9.9(1.6-26.3)$ & $<0.0001$ \\
\hline POD 5 & $10.5(0.4-27.8)$ & $3.9(0.3-21.0)$ & $<0.0001$ \\
\hline \multicolumn{4}{|c|}{ Amylase levels of drainage fluid, median (range), U/l } \\
\hline POD 1 & $791(11-32,214)$ & $268(17-41,735)$ & 0.984 \\
\hline POD 3 & $375(2-19,041)$ & $306(5-10,014)$ & 0.271 \\
\hline \multicolumn{4}{|l|}{ Type of complication } \\
\hline \multicolumn{4}{|l|}{ POPF, n $(\%)$} \\
\hline Grade A & $16(14 \%)$ & $10(26 \%)$ & 0.094 \\
\hline CR-PF & $46(39 \%)$ & $4(10 \%)$ & $<0.0001$ \\
\hline Delayed gastric emptying, n (\%) & $20(17 \%)$ & $3(8 \%)$ & 0.128 \\
\hline Infectious complication, $\mathrm{n}(\%)$ & $46(39 \%)$ & $5(13 \%)$ & 0.012 \\
\hline Wound infection, n (\%) & $30(26 \%)$ & $4(10 \%)$ & 0.032 \\
\hline Intra-abdominal abscess, $\mathrm{n}(\%)$ & $23(20 \%)$ & $1(3 \%)$ & 0.003 \\
\hline Sepsis, n (\%) & $6(5 \%)$ & $0(0 \%)$ & 0.06 \\
\hline Catheter fever, n (\%) & $5(4 \%)$ & $0(0 \%)$ & 0.087 \\
\hline Hospital stay, median (range), days & $32(14-160)$ & $29(17-63)$ & 0.063 \\
\hline
\end{tabular}

ERBD: Endoscopic retrograde biliary drainage; ENBD: endoscopic nasobiliary drainage; POPF: postoperative pancreatic fistula; POD: postoperative day; CR-PF: clinically relevant pancreatic fistula.

Univariate and multivariate analyses were performed to identify risk factors for postoperative infectious complications and CR-PF (Table III). The multivariate analysis showed that age $(\geq 70)$ [odds ratio $(\mathrm{OR})=3.72$; $p=0.001]$, the presence of preoperative cholangitis $(\mathrm{OR}=2.74$; $p=0.015)$ and $\mathrm{ERBD}(\mathrm{OR}=3.99 ; p=0.0008)$ were independent risk factors for postoperative infectious complications. On the other hand, male sex $(\mathrm{OR}=3.43 ; p=0.008)$, pancreatic texture (soft) $(\mathrm{OR}=16.69 ; \quad p=0.0002)$, presence of preoperative cholangitis $(\mathrm{OR}=2.64 ; p=0.031)$, and $\mathrm{ERBD}$ $(\mathrm{OR}=11.42 ; p<0.0001)$ were found to be independent risk factors for CR-PF. It was shown that ERBD and the presence of preoperative cholangitis were the common risk factors for postoperative infectious complications and CR-PF.

In 47 of the 109 patients with ERBD, and in 25 of the 47 patients with ENBD, the bile juice was sampled. Positive bile juice cultures were found in all patients with ERBD (100\%), but only in 13 of $25(64 \%)$ patients with ENBD. The incidence of bile juice infection was significantly higher in patients with ERBD than in patients with ENBD. Enterococcus and Enterobacter species were the most frequent bacteria in the positive cultures in both groups (Table IV).

There was a distinct difference in the duration of drainage between patients with ERBD and ENBD. Therefore, the incidence of infectious complications was investigated by the duration of drainage (Table V). It was found that the incidence of infectious complications and CR-PF was significantly higher in patients with ERBD than in patients with ENBD when the duration of drainage was within 30 days. However, there was no significant difference between the two groups when the duration of drainage exceeded 30 days.

\section{Discussion}

Although preoperative biliary drainage (PBD) may increase infectious complications (6-10), and it is advocated that jaundiced patients who will undergo PD should not be routinely drained before surgery, PBD is often inevitable because of cholangitis, the need for preoperative diagnosis, or when there is an indication for neoadjuvant therapy in clinical practice. Therefore, it is necessary to determine the best approach to PBD in patients who have a strong indication for PBD in whom early surgery is not feasible. In this study, the incidence rates of postoperative infectious complications and CR-PF were found to be significantly higher in patients receiving ERBD than in patients receiving ENBD.

Lee et al. evaluated the impact of PBD and of the type of the PBD on short-term surgical outcomes using propensity score matching (19). They reported that the overall complication rate was significantly higher in patients who underwent PBD, and the incidences of postoperative wound 
in vivo $36: 391-397(2022)$

Table III. Univariate and multivariate analyses of risk factors for postoperative infectious complications and CR-PF.

\begin{tabular}{|c|c|c|c|c|c|c|c|c|c|c|c|c|}
\hline & \multicolumn{6}{|c|}{ Infectious complications } & \multicolumn{6}{|c|}{ CR-PF } \\
\hline & \multirow{2}{*}{$\begin{array}{c}(+) \\
\mathrm{n}=51\end{array}$} & \multirow{2}{*}{$\frac{(-)}{\mathrm{n}=105}$} & \multirow{2}{*}{$\frac{\text { Univariate }}{p \text {-Value }}$} & \multicolumn{3}{|c|}{ Multivariate } & \multirow{2}{*}{$\frac{(+)}{n=59}$} & \multirow{2}{*}{$\frac{(-)}{n=97}$} & \multirow{2}{*}{$\frac{\text { Univariate }}{p \text {-Value }}$} & \multicolumn{3}{|c|}{ Multivariate } \\
\hline & & & & $\mathrm{OR}$ & $95 \% \mathrm{CI}$ & $p$-Value & & & & OR & $95 \% \mathrm{CI}$ & $p$-Value \\
\hline $\begin{array}{l}\text { Gender } \\
\text { (male, \%) }\end{array}$ & $37(73)$ & $55(52)$ & 0.015 & 1.50 & $0.63-3.63$ & 0.355 & $43(73)$ & $49(51)$ & 0.005 & 3.43 & $1.37-9.11$ & 0.008 \\
\hline $\begin{array}{l}\text { Age } \\
(\geq 70 \text { years, } \%)\end{array}$ & $36(71)$ & $43(41)$ & 0.0004 & 3.72 & $1.66-8.79$ & 0.001 & $35(59)$ & $44(45)$ & 0.09 & & & \\
\hline $\begin{array}{l}\text { Body mass index } \\
\left(\geq 22 \mathrm{~kg} / \mathrm{m}^{2}, \%\right)\end{array}$ & $31(61)$ & $37(35)$ & 0.003 & 2.15 & $0.96-4.86$ & 0.061 & $31(53)$ & $37(38)$ & 0.079 & & & \\
\hline $\begin{array}{l}\text { Histology } \\
\text { (pancreatic } \\
\text { cancer, \%) }\end{array}$ & $24(47)$ & $63(60)$ & 0.127 & & & & $18(31)$ & $69(71)$ & $<0.0001$ & 1.74 & $0.61-4.98$ & 0.299 \\
\hline $\begin{array}{r}\text { Pancreatic texture } \\
\text { (soft pancreas, \%) }\end{array}$ & $37(73)$ & $62(59)$ & 0.093 & & & & $55(93)$ & $44(45)$ & $<0.0001$ & 16.69 & $3.58-93.04$ & 0.0002 \\
\hline $\begin{array}{l}\text { Preoperative } \\
\text { cholangitis } \\
\text { (present, \%) }\end{array}$ & $33(65)$ & $39(35)$ & 0.001 & 2.74 & $1.22-6.32$ & 0.015 & $38(64)$ & $34(35)$ & 0.0003 & 2.64 & $1.09-6.56$ & 0.031 \\
\hline $\begin{array}{l}\text { Diameter of MPD } \\
(<3 \mathrm{~mm}, \%)\end{array}$ & $34(67)$ & $50(48)$ & 0.024 & 2.00 & $0.88-4.67$ & 0.099 & $46(78)$ & $38(39)$ & $<0.0001$ & 1.14 & $0.34-3.68$ & 0.825 \\
\hline $\begin{array}{l}\text { Operative time } \\
(\geq 500 \mathrm{~min}, \%)\end{array}$ & $33(65)$ & $48(46)$ & 0.025 & 1.53 & $0.60-3.94$ & 0.375 & $31(53)$ & $50(52)$ & 0.904 & & & \\
\hline $\begin{array}{l}\text { Blood loss } \\
(\geq 700 \mathrm{ml}, \%)\end{array}$ & $34(67)$ & $47(45)$ & 0.009 & 2.04 & $0.79-5.46$ & 0.140 & $32(54)$ & $49(51)$ & 0.652 & & & \\
\hline $\begin{array}{l}\text { Type of drainage } \\
(\text { ERBD } \%)\end{array}$ & $46(90)$ & $71(68)$ & 0.001 & 3.99 & $1.41-13.28$ & 0.008 & $55(93)$ & $62(64)$ & $<0.0001$ & 11.98 & $3.86-46.76$ & $<0.0001$ \\
\hline
\end{tabular}

CR-PF: Clinically relevant pancreatic fistula; POPF: postoperative pancreatic fistula; OR: odds ratio; CI: confidence interval; ERBD: endoscopic retrograde biliary drainage; MPD: main pancreatic duct.

infections and postoperative pancreatic fistula (POPF) were significantly higher in patients who underwent endoscopic drainage than in those who underwent transhepatic biliary drainage (PTBD). They concluded that PBD, especially endoscopic drainage, should not be routinely performed in patients with periampullary cancer. Although PTBD was not investigated in the present study, considering that ENBD provides the same external drainage as PTBD, these results supported the finding that ENBD is superior to ERBD regarding postoperative complications. Fujii et al. also reported ERBD caused postoperative complications, including POPF, and infectious postoperative complications were more frequent than ENBD (20). One serious problem of PBD is infectious complications. Internal drainage quite often leads to infection of the biliary tract (21), although it allows normal bile flow and maintains an intestinal barrier from the perspective of intestinal immunity and the prevention of bacterial translocation $(22,23)$. In contrast, external drainage, such as PTBD and ENBD, reduces the risk of ascending infection in comparison to internal drainage, in which the stent is placed in the duodenum. Furthermore, ascending infection easily occurs after EST, which is performed more frequently in ERBD than ENBD. Indeed, in
Table IV. Results of bile juice cultures.

\begin{tabular}{lccc}
\hline & $\begin{array}{l}\text { ERBD } \\
(\mathrm{n}=47)\end{array}$ & $\begin{array}{l}\text { ENBD } \\
(\mathrm{n}=25)\end{array}$ & $p$-Value \\
\hline Positive, n (\%) & $47(100 \%)$ & $16(64 \%)$ & $<0.0001$ \\
Bacteria & 29 & 11 & \\
Enterococcus & 17 & 7 & \\
$\quad$ Enterobacter & 14 & 5 & \\
Klebsiella & 8 & 1 & \\
Streptococcus & 3 & 2 & \\
E. coli & 3 & 1 & \\
Citrobacter & 2 & 1 & \\
Staphylococcus & 2 & 1 & \\
Pseudomonas & 0 & 2 & \\
Serratia & &
\end{tabular}

ERBD: Endoscopic retrograde biliary drainage; ENBD: endoscopic nasobiliary drainage.

this study, the incidence of infection of the bile juice that was sampled during operation was significantly higher in patients with ERBD than in patients with ENBD.

Several risk factors for CR-PF have been determined, such as male sex, soft gland texture of the pancreas, non-pancreatic 
Table V. Incidences of infectious complication and CR-PF by period of duration of drainage.

\begin{tabular}{|c|c|c|c|c|c|c|}
\hline & \multicolumn{3}{|c|}{$\leq 30$ days } & \multicolumn{3}{|c|}{$>30$ days } \\
\hline & ERBD $(n=49)$ & $\operatorname{ENBD}(n=25)$ & $p$-Value & ERBD $(n=68)$ & $\operatorname{ENBD}(n=14)$ & $p$-Value \\
\hline Infectious complication, $\mathrm{n}(\%)$ & $15(31 \%)$ & $2(8 \%)$ & 0.020 & $31(46 \%)$ & $3(21 \%)$ & 0.083 \\
\hline POPF (grade B/C), n (\%) & $25(51 \%)$ & $1(4 \%)$ & $<0.0001$ & $30(56 \%)$ & $3(21 \%)$ & 0.103 \\
\hline
\end{tabular}

CR-PF: Clinically relevant pancreatic fistula; ERBD: endoscopic retrograde biliary drainage; ENBD: endoscopic nasobiliary drainage; POPF: postoperative pancreatic fistula.

cancer, small pancreatic duct diameter, high intraoperative blood loss, tumor location, interrupted anastomosis and drain amylase level on postoperative day $1>4,000$ IU/1 (24-27). Recently, in addition, it has been reported that bacterial contamination in ascitic fluid was significantly associated with the development of CR-PF (13). It is hypothesized that endogenous enteric bacteria are the main cause of bacterial contamination in ascitic fluid. Furthermore, Ohgi et al. suggested that the bacteria in the ascitic fluid were derived from bacterobilia and might trigger CR-PF, because the microorganisms detected in the drainage fluid usually corresponded to the microorganisms isolated from the bile of patients with positive intraoperative bile cultures (14). Kajiwara et al. also reported that bile juice infection on postoperative day 1 was a significant risk factor for CR-PF, and it was significantly associated with retrograde biliary drainage, although performance of biliary drainage was not a significant risk factor for CR-PF (12). Recent studies demonstrated that bacteria were detected in the bile of 75$97 \%$ of patients who underwent PBD (28-30). Scheufele et al. reported that a positive intraoperative bile culture was observed in almost all patients after PBD, and PBD was associated with more antibiotic-resistant bacteria in the bile, such as Enterococcus species (30). However, all of these authors performed PBD only by ERBD. The present study demonstrated that the incidence of bile juice infection was significantly higher in patients with ERBD than in patients with ENBD, which suggests that retrograde infection and bacterobilia occurs more frequently in patients with ERBD. Therefore, it is obvious that the incidence of postoperative CR-PF was significantly higher in patients with ERBD than in patients with ENBD in the present study, considering that bacterial infections are correlated with the onset of CR-PF.

Some authors advocated delaying surgery for up to one month after PBD to reduce postoperative morbidity $(31,32)$, although the appropriate duration of PBD is still controversial. Shin et al. compared an early surgery group ( $\leq 2$ weeks) and a late surgery group ( $\geq 3$ weeks) after PBD, and they found that major complications of Clavien-Dindo grade II or higher occurred more frequently in the late surgery group (33). Fujii et al. also recently reported that receiver operating characteristic curve analysis for the preoperative drainage period in ERBD patients determined that the cutoff level for the onset of POPF was 29 days (20). In the present study, there was no significant difference between the patients who underwent ERBD and those who underwent ENBD when the period of PBD exceeded 30 days, although the incidences of infectious complications and CR-PF were significantly higher in patients with ERBD when the duration of drainage was within 30 days. This finding indicates that retrograde infection occurs even in patients with ENBD as well as those with ERBD when the duration of drainage becomes longer.

On multivariate analysis, it was found that ERBD and the presence of preoperative cholangitis were the common significant risk factors for postoperative infectious complications and CR-PF. These results mean that infected bile juice is at the root of these complications. In fact, intraoperative bile cultures showed that the incidence of bile juice infection was significantly higher in patients with ERBD than that in patients with ENBD, which could be explained by the easy occurrence of retrograde infection in ERBD. Therefore, it is considered that ERBD should be avoided, especially when preoperative cholangitis is present.

There are some limitations to this study, because it was retrospective and had a heterogeneous group of subjects from a single institution. First, inevitable selection bias might exist, because which type of PBD to perform was decided by the internist or surgeons. However, there were no significant differences with respect to clinical characteristics between the patients who underwent ENBD and those who underwent ERBD, except for sex, in this study. Second, the duration of drainage was not decided by clear criteria. Actually, the duration of drainage was significantly shorter in patients who underwent ENBD. Therefore, further investigation based on the period of drainage should be performed. Though this retrospective study had these limitations, it demonstrated the superiority of ENBD over ERBD with respect to the incidences of postoperative infectious complications and CR-PF.

In conclusion, ERBD was associated with higher incidence of postoperative infectious complications and CR- 
PF following PD than ENBD. ERBD should not be performed because of the increased rate of infectious complications and CR-PF following PD, and ENBD should be chosen instead. Furthermore, it is recommended to perform PD within thirty days of ENBD period.

\section{Conflicts of Interest}

There are no conflicts of interest related to this study and no financial or material support.

\section{Authors' Contributions}

Study design: Satoh, Matuskawa. Acquisition of data: Shiozaki. Drafting of manuscript: Satoh, Manuscript editing: Shiozaki.

\section{References}

1 Dixon JM, Armstrong CP, Duffy SW and Davies GC: Factors affecting morbidity and mortality after surgery for obstructive jaundice: a review of 373 patients. Gut 24(9): 845-852, 1983. PMID: 6604001. DOI: 10.1136/gut.24.9.845

2 Greig JD, Krukowski ZH and Matheson NA: Surgical morbidity and mortality in one hundred and twenty-nine patients with obstructive jaundice. Br J Surg 75(3): 216-219, 1988. PMID: 3349328. DOI: 10.1002/bjs.1800750309

3 Pitt HA, Cameron JL, Postier RG and Gadacz TR: Factors affecting mortality in biliary tract surgery. Am J Surg 141(1): 66-72, 1981. PMID: 6970004. DOI: 10.1016/0002-9610(81)900 14-3

4 Kruse EJ: Palliation in pancreatic cancer. Surg Clin North Am 90(2): 355-364, 2010. PMID: 20362791. DOI: 10.1016/j.suc. 2009.12.004

5 Pavlidis ET and Pavlidis TE: Pathophysiological consequences of obstructive jaundice and perioperative management. Hepatobiliary Pancreat Dis Int 17(1): 17-21, 2018. PMID: 29428098. DOI: 10.1016/j.hbpd.2018.01.008

6 Limongelli P, Pai M, Bansi D, Thiallinagram A, Tait P, Jackson J, Habib NA, Williamson RC and Jiao LR: Correlation between preoperative biliary drainage, bile duct contamination, and postoperative outcomes for pancreatic surgery. Surgery 142(3): 313318, 2007. PMID: 17723881. DOI: 10.1016/j.surg.2007.04.022

7 Garcea G, Chee W, Ong SL and Maddern GJ: Preoperative biliary drainage for distal obstruction: the case against revisited. Pancreas 39(2): 119-126, 2010. PMID: 19940799. DOI: 10.1097/MPA.0b013e3181bd65de

8 Povoski SP, Karpeh MS Jr, Conlon KC, Blumgart LH and Brennan MF: Association of preoperative biliary drainage with postoperative outcome following pancreaticoduodenectomy. Ann Surg 230(2): 131-142, 1999. PMID: 10450725. DOI: $10.1097 /$ 00000658-199908000-00001

9 Pisters PW, Hudec WA, Hess KR, Lee JE, Vauthey JN, Lahoti S, Raijman I and Evans DB: Effect of preoperative biliary decompression on pancreaticoduodenectomy-associated morbidity in 300 consecutive patients. Ann Surg 234(1): 47-55, 2001. PMID: 11420482. DOI: 10.1097/00000658-200107000-00008

10 De Pastena M, Marchegiani G, Paiella S, Malleo G, Ciprani D, Gasparini C, Secchettin E, Salvia R, Gabbrielli A and Bassi C:
Impact of preoperative biliary drainage on postoperative outcome after pancreaticoduodenectomy: An analysis of 1500 consecutive cases. Dig Endosc 30(6): 777-784, 2018. PMID: 29943483. DOI: $10.1111 /$ den.13221

11 Srivastava S, Sikora SS, Kumar A, Saxena R and Kapoor VK: Outcome following pancreaticoduodenectomy in patients undergoing preoperative biliary drainage. Dig Surg 18(5): 381387, 2001. PMID: 11721113. DOI: 10.1159/000050178

12 Kajiwara T, Sakamoto Y, Morofuji N, Nara S, Esaki M, Shimada $\mathrm{K}$ and Kosuge T: An analysis of risk factors for pancreatic fistula after pancreaticoduodenectomy: clinical impact of bile juice infection on day 1. Langenbecks Arch Surg 395(6): 707-712, 2010. PMID: 19655161. DOI: 10.1007/s00423-009-0547-z

13 Nagakawa Y, Matsudo T, Hijikata Y, Kikuchi S, Bunso K, Suzuki Y, Kasuya K and Tsuchida A: Bacterial contamination in ascitic fluid is associated with the development of clinically relevant pancreatic fistula after pancreatoduodenectomy. Pancreas 42(4): 701-706, 2013. PMID: 23429497. DOI: 10.1097/MPA.0b013e31826d3a41

14 Ohgi K, Sugiura T, Yamamoto Y, Okamura Y, Ito T and Uesaka $\mathrm{K}$ : Bacterobilia may trigger the development and severity of pancreatic fistula after pancreatoduodenectomy. Surgery 160(3): 725-730, 2016. PMID: 27233637. DOI: 10.1016/j.surg. 2016.03 .032

15 Hata T, Mizuma M, Motoi F, Nakagawa K, Masuda K, Ishida M, Morikawa T, Hayashi H, Kamei T, Naitoh T and Unno M: Early postoperative drainage fluid culture positivity from contaminated bile juice is predictive of pancreatic fistula after pancreaticoduodenectomy. Surg Today 50(3): 248-257, 2020. PMID: 31583471. DOI: 10.1007/s00595-019-01885-8

16 van der Gaag NA, Rauws EA, van Eijck CH, Bruno MJ, van der Harst E, Kubben FJ, Gerritsen JJ, Greve JW, Gerhards MF, de Hingh IH, Klinkenbijl JH, Nio CY, de Castro SM, Busch OR, van Gulik TM, Bossuyt PM and Gouma DJ: Preoperative biliary drainage for cancer of the head of the pancreas. N Engl J Med 362(2): 129-137, 2010. PMID: 20071702. DOI: 10.1056/ NEJMoa0903230

17 Jagannath P, Dhir V, Shrikhande S, Shah RC, Mullerpatan P and Mohandas KM: Effect of preoperative biliary stenting on immediate outcome after pancreaticoduodenectomy. Br J Surg 92(3): 356-361, 2005. PMID: 15672425. DOI: 10.1002/bjs.4864

18 Dindo D, Demartines N and Clavien PA: Classification of surgical complications: a new proposal with evaluation in a cohort of 6336 patients and results of a survey. Ann Surg 240(2): 205-213, 2004. PMID: 15273542. DOI: 10.1097/01.sla.0000 133083.54934.ae

19 Lee H, Han Y, Kim JR, Kwon W, Kim SW and Jang JY: Preoperative biliary drainage adversely affects surgical outcomes in periampullary cancer: a retrospective and propensity scorematched analysis. J Hepatobiliary Pancreat Sci 25(3): 206-213, 2018. PMID: 29222963. DOI: 10.1002/jhbp.529

20 Fujii T, Yamada S, Suenaga M, Kanda M, Takami H, Sugimoto H, Nomoto S, Nakao A and Kodera Y: Preoperative internal biliary drainage increases the risk of bile juice infection and pancreatic fistula after pancreatoduodenectomy: a prospective observational study. Pancreas 44(3): 465-470, 2015. PMID: 25423556. DOI: 10.1097/MPA.0000000000000265

21 Rerknimitr R, Attasaranya S, Kladchareon N, Mahachai V and Kullavanijaya P: Feasibility and complications of endoscopic biliary drainage in patients with malignant biliary obstruction at 
King Chulalongkorn Memorial Hospital. J Med Assoc Thai 85 Suppl 1: S48-S53, 2002. PMID: 12188451.

22 Ogata Y, Nishi M, Nakayama H, Kuwahara T, Ohnishi Y and Tashiro S: Role of bile in intestinal barrier function and its inhibitory effect on bacterial translocation in obstructive jaundice in rats. J Surg Res 115(1): 18-23, 2003. PMID: 14572768. DOI: $10.1016 / \mathrm{s} 0022-4804(03) 00308-1$

23 Kamiya S, Nagino M, Kanazawa H, Komatsu S, Mayumi T, Takagi K, Asahara T, Nomoto K, Tanaka R and Nimura Y: The value of bile replacement during external biliary drainage: an analysis of intestinal permeability, integrity, and microflora. Ann Surg 239(4): 510-517, 2004. PMID: 15024312. DOI: 10.1097/ 01.sla.0000118594.23874.89

24 Callery MP, Pratt WB, Kent TS, Chaikof EL and Vollmer CM Jr: A prospectively validated clinical risk score accurately predicts pancreatic fistula after pancreatoduodenectomy. J Am Coll Surg 216(1): 1-14, 2013. PMID: 23122535. DOI: 10.1016/j.jamcollsurg.2012.09.002

25 Kawai M, Kondo S, Yamaue H, Wada K, Sano K, Motoi F, Unno M, Satoi S, Kwon AH, Hatori T, Yamamoto M, Matsumoto J, Murakami Y, Doi R, Ito M, Miyakawa S, Shinchi H, Natsugoe $\mathrm{S}$, Nakagawara H, Ohta T and Takada T: Predictive risk factors for clinically relevant pancreatic fistula analyzed in 1,239 patients with pancreaticoduodenectomy: multicenter data collection as a project study of pancreatic surgery by the Japanese Society of Hepato-Biliary-Pancreatic Surgery. J Hepatobiliary Pancreat Sci 18(4): 601-608, 2011. PMID: 21491103. DOI: $10.1007 / \mathrm{s} 00534-011-0373-\mathrm{x}$

26 Chen JS, Liu G, Li TR, Chen JY, Xu QM, Guo YZ, Li M and Yang L: Pancreatic fistula after pancreaticoduodenectomy: Risk factors and preventive strategies. J Cancer Res Ther 15(4): 857 863, 2019. PMID: 31436243. DOI: 10.4103/jcrt.JCRT_364_18

27 Kawaida H, Kono H, Hosomura N, Amemiya H, Itakura J, Fujii $\mathrm{H}$ and Ichikawa D: Surgical techniques and postoperative management to prevent postoperative pancreatic fistula after pancreatic surgery. World J Gastroenterol 25(28): 3722-3737, 2019. PMID: 31391768. DOI: 10.3748/wjg.v25.i28.3722

28 Sudo T, Murakami Y, Uemura K, Hayashidani Y, Hashimoto Y, Ohge $\mathrm{H}$ and Sueda T: Specific antibiotic prophylaxis based on bile cultures is required to prevent postoperative infectious complications in pancreatoduodenectomy patients who have undergone preoperative biliary drainage. World J Surg 31(11): 2230-2235, 2007. PMID: 17726628. DOI: 10.1007/s00268-0079210-4
29 Nomura T, Shirai Y and Hatakeyama K: Enterococcal bactibilia in patients with malignant biliary obstruction. Dig Dis Sci 45(11): 2183-2186, 2000. PMID: 11215736. DOI: 10.1023/ a: 1026640603312

30 Scheufele F, Aichinger L, Jäger C, Demir IE, Schorn S, Sargut M, Erkan M, Kleeff J, Friess H and Ceyhan GO: Effect of preoperative biliary drainage on bacterial flora in bile of patients with periampullary cancer. Br J Surg 104(2): e182-e188, 2017. PMID: 28121036. DOI: 10.1002/bjs.10450

31 Choi YM, Cho EH, Lee KY, Ahn SI, Choi SK, Kim SJ, Hur YS, Cho YU, Hong KC, Shin SH, Kim KR and Woo ZH: Effect of preoperative biliary drainage on surgical results after pancreaticoduodenectomy in patients with distal common bile duct cancer: focused on the rate of decrease in serum bilirubin. World J Gastroenterol 14(7): 1102-1107, 2008. PMID: 18286694. DOI: $10.3748 /$ wjg.14.1102

32 Sandini M, Honselmann KC, Birnbaum DJ, Gavazzi F, Chirica M, Wellner U, Guilbaud T, Bolm L, Angrisani M, Moutardier V, Cereda M, Girard É, Montorsi M, Keck T, Zerbi A and Gianotti L: Preoperative biliary stenting and major morbidity after pancreatoduodenectomy: Does elapsed time matter?: The FRAGERITA study group. Ann Surg 268(5): 808-814, 2018. PMID: 30303874. DOI: 10.1097/SLA.0000000000002838

33 Shin SH, Han IW, Ryu Y, Kim N, Choi DW and Heo JS: Optimal timing of pancreaticoduodenectomy following preoperative biliary drainage considering major morbidity and postoperative survival. J Hepatobiliary Pancreat Sci 26(10): 449458, 2019. PMID: 31265173. DOI: 10.1002/jhbp.652
Received September 5, 2021

Revised October 23, 2021

Accepted October 25, 2021 